The University of Akron

\title{
IdeaExchange@UAkron
}

Proceedings from the Document Academy

University of Akron Press Managed

December 2018

\section{Image and Range-Based 3D Acquisition and Modeling of Popular Musical Instruments}

Giacomo Patrucco

Polytechnic University of Turin, giacomo.patrucco@polito.it

Filiberto Chiabrando

Polytechnic University of Turin, filiberto.chiabrando@polito.it

Piercarlo Dondi

University of Pavia, piercarlo.dondi@unipvit

Marco Malagodi

University of Pavia, marco.malagodi@unipv.it

Please take a moment to share how this work helps you through this survey. Your feedback will be important as we plan further development of our repository.

Follow this and additional works at: https://ideaexchange.uakron.edu/docam

Part of the Digital Humanities Commons, Historic Preservation and Conservation Commons, and the Museum Studies Commons

\section{Recommended Citation}

Patrucco, Giacomo; Chiabrando, Filiberto; Dondi, Piercarlo; and Malagodi, Marco (2018) "Image and Range-

Based 3D Acquisition and Modeling of Popular Musical Instruments," Proceedings from the Document Academy: Vol.

5 : Iss. 2 , Article 9.

DOI: https://doi.org/10.35492/docam/5/2/9

Available at: https://ideaexchange.uakron.edu/docam/vol5/iss2/9

This Conference Proceeding is brought to you for free and open access by University of Akron Press Managed at IdeaExchange@UAkron, the institutional repository of The University of Akron in Akron, Ohio, USA. It has been accepted for inclusion in Proceedings from the Document Academy by an authorized administrator of

IdeaExchange@UAkron.For more information, please contact mjon@uakron.edu, uapress@uakron.edu. 


\section{Introduction}

In the last few years, the possibilities offered by the new web and mobile technologies for 3D visualisation allowed an increasingly rapid dissemination of 3D models and data connected to movable and unmovable objects. This approach is nowadays popular in the Cultural Heritage field, and many museums all over the world are digitalizing their artworks (Guidi et al. 2017; Povroznik 2017; Kersten et al. 2016).

In this scenario, the most critical part is surely the realization of faithful 3D models able to reproduce the shape of the analyzed objects. The most used methodologies are the so-called image-based and range-based modeling techniques (Remondino 2011; Di Pietra et al. 2017; Adami et al. 2015). The first one is commonly connected to the use of digital images processed using a photogrammetric computer vision approach (Structure from Motion); instead, the latter involves the acquisition of three-dimensional geometrical shapes of the object using active sensors, and it is usually performed using LiDAR (Light Detection and Ranging) instruments also commonly called laser scanner (Chiabrando and Spanò 2013, Dondi et al. 2017). The current work presents the results obtained using the two aforementioned techniques for the digitalization of a series of musical instruments and sound devices held in the Museo del Paesaggio Sonoro in Riva presso Chieri (Torino, Italy).

Since the goal was the realization of very accurate replicas (models with a submillimeter accuracy) of these instruments, both for dissemination purposes and for research analyses, in order to realize the 3D models a high-resolution triangulation-based laser scanner was used, and a photogrammetric acquisition with a 50.3 MPixel digital camera has been performed.

The achieved results will be discussed with a complete evaluation of the two followed methodologies, considering the quality and the accuracy of the final 3D models, the processing workflow, and the usability and the effectiveness of the realized models in terms of dissemination, scientific analysis and improvement of knowledge with respect to traditional examinations.

\section{The SAMIC project}

This research experience takes place in the framework of the SAMIC project (Sound Archives \& Musical Instruments Collection) coordinated by Dr. Ilario Meandri (University of Turin).

The aim of the project is the creation of the first national CMS (Content Management System) and the first Linked Open Data system dedicated to digital cataloguing of music instruments. 
Besides University of Turin, also Polytechnic University of Turin and University of Pavia are involved in the project, specifically Geomatics Lab for Cultural Heritage (Turin) and Arvedi Laboratory of Non-Invasive Diagnostics (Pavia).

Geomatics Lab for Cultural Heritage develops its research activity in the framework of applications of Geomatics techniques for Cultural Heritage documentation.

The main topics of the Lab are the following:

- 3D metric survey techniques: terrestrial LiDAR, rapid mapping technologies, close-range photogrammetry and aerial photogrammetry (traditional and through the use of drones).

- 3D modelling of built heritage and movable heritage.

- Realisation of GIS (Geographic Information System) and WebGIS projects for Cultural Heritage and landscape.

The mission of Arvedi Laboratory is the study and the characterization of historical musical instruments (with a special focus on violins) through the use and implementation of advanced non-invasive diagnostic techniques. The aim of the analyses will be to determine the state of conservation of the artifacts, map any phases of alteration that are present, characterize the materials of which they are made up (such as varnishes) and study their dimensions and morphology.

The goal of the two Labs in this project was the creation of high-resolution 3D models of these instruments belonging to the collection of "Museo del Paesaggio Sonoro" (Riva presso Chieri, TO), a valuable example of the so-called movable heritage.

In recent years, the development of new technologies has provided effective tools for Cultural Heritage documentation and in fact the aim was to digitalise these music instruments thanks to modern 3D acquisition techniques and strategies. The objectives of the creation of these 3D databases were multiples:

- Documentation of cultural and movable heritage.

- 3D visualisation of the models (thanks to mobile technologies and online open-source 3D viewers).

- Digital interrogation.

- Implementation of the models for augmented/virtual reality experiences.

- Dissemination.

\section{The case studies}

In the framework of the project a test was performed with nine music instruments (Fig. 1) selected from the collection of "Museo del Paesaggio Sonoro". The chosen music instruments are the following: a torototela, a clay whistle, a whirling disc (called frullo), a noisemaker for the Holy Week (called tabella), a bull roarer, two hunting calls for quails and two idiophonic mirlitons (called cusa). In some cases, 
the instruments were composed by more than one element (for example, the torototela is composed by a shovel and a pig's bladder; the whirling disc is fitted with a couple of handles; each of the two idiophonic mirlitons has a top part and a bottom part).

It has therefore necessary to consider separately each of these elements, during the acquisition phase of the datasets, the data processing phase and the model generation of each model. The 3D models of the elements that make up the same instrument were successively joined together.

In total fourteen 3D models have been generated.
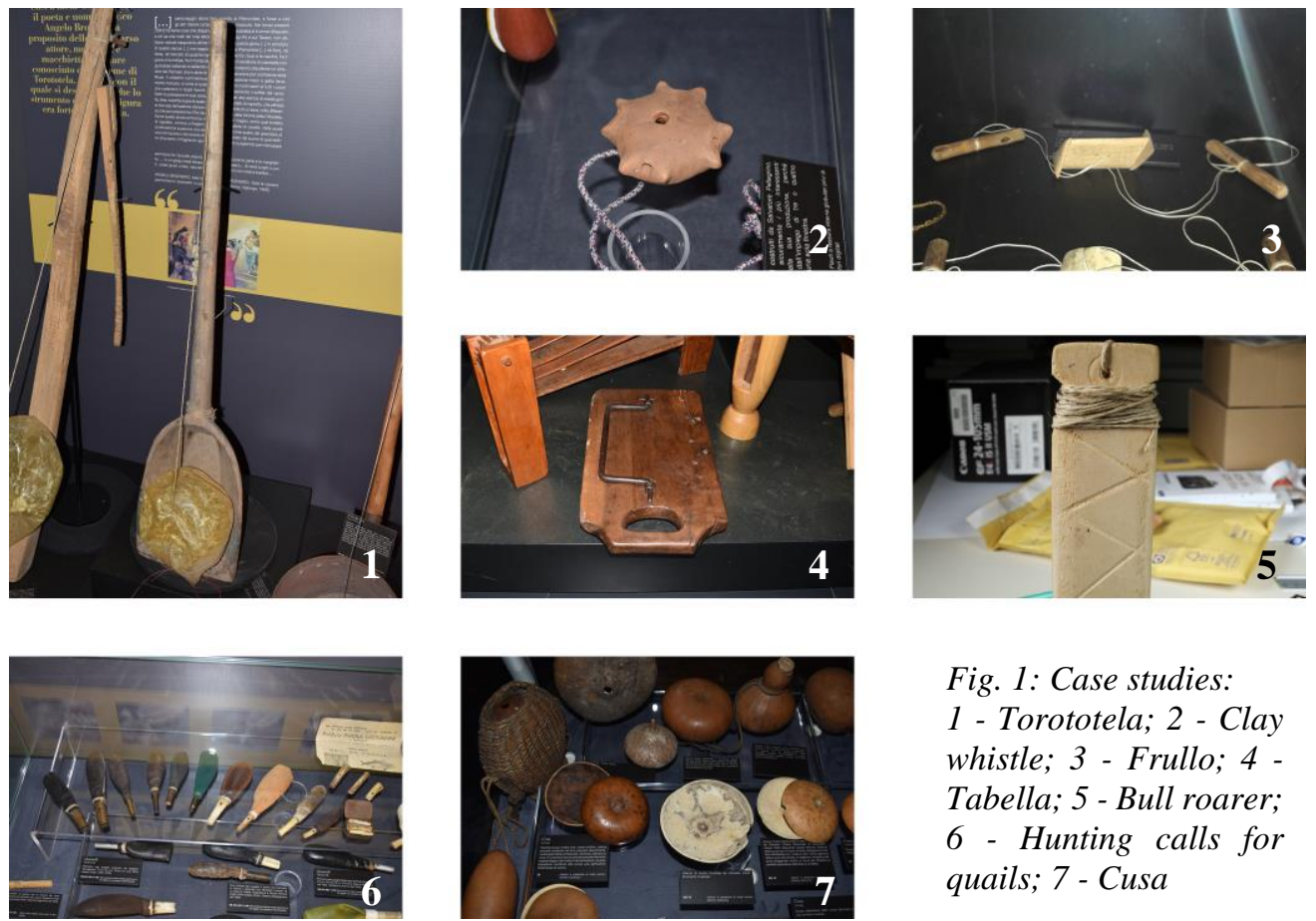

Fig. 1: Case studies:

1 - Torototela; 2 - Clay whistle; 3 - Frullo; 4 Tabella; 5 - Bull roarer; 6 - Hunting calls for quails; 7 - Cusa

\section{Methods and instruments}

As stated above, two different approaches were chosen in order to digitalise the popular music instruments. The group of Arvedi Laboratory of Non-Invasive Diagnostics (University of Pavia) used an active sensor, a LiDAR system (a 3D triangulation laser scanner), while the group of Geomatics Lab for Cultural Heritage (Polytechnic University of Turin) use a passive sensor (a high-resolution full frame digital camera). In both cases the aim of the work was the creation of a very detailed $3 \mathrm{D}$ model, usually formed by an high-resolution mesh. A mesh is a 
continuous digital surface formed by a large number of polygons that approximates in the best way the surface of a 3D object (Campomanes-Alvarez et al. 2012).

The LiDAR instrument employed during this experience is an Integrated scanner RS3 (a triangulation-based laser scanner with a stated accuracy of $30 \mu \mathrm{m}$ ), mounted on a mobile arm with 7 degrees of freedom (Romer Absolute Arm 7-Axis "SI") both produced by Hexagon Metrology (Fig. 2-3). This type of high-resolution scanner can produce accurate 3D models in scale 1:1 without textures. It can work with both reflective and non-reflective surfaces (Dondi et al. 2016, Dondi et al. 2017).
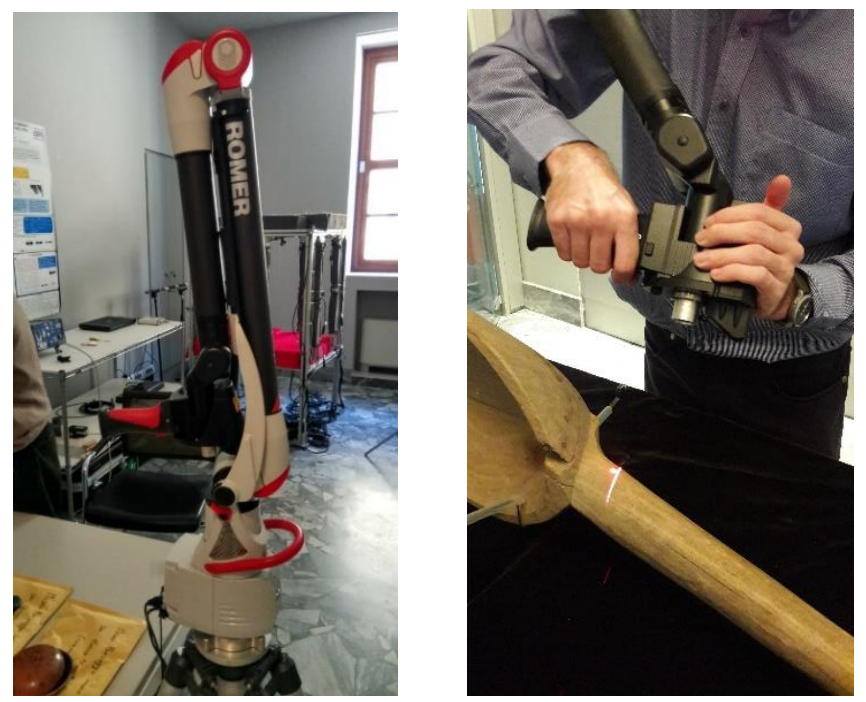

Fig. 2-3: On the left, the RS3 Integrated Scanner mounted on Romer Absolute Arm 7-Axis 'SI'. On the right, an acquisition performed with the laser scanner.

\begin{tabular}{|l|l|}
\hline Model & Integrated scanner RS3 \\
\hline Max. point acquisition rate & $460.000[$ point/s] \\
\hline Points per Line & 4600 \\
\hline Line rate & $100[\mathrm{hz}]$ \\
\hline Line width range & $\begin{array}{l}\min .46[\mathrm{~mm}] \\
\operatorname{mid} .65[\mathrm{~mm}] \\
\\
\max .89[\mathrm{~mm}]\end{array}$ \\
\hline Minimum point spacing (mid-range) & $0.014[\mathrm{~mm}]$ \\
\hline Laser safety & Class $2 \mathrm{M}$ \\
\hline Accuracy & $30[\mu \mathrm{m}]$ \\
\hline
\end{tabular}

Table 1: Main characteristic of the Romer RS3 Integrated Scanner 
On the other hand, the close-range image acquisition was realized using a Canon EOS 5DSR equipped with a Zeiss $50 \mathrm{~mm}$ macro lens (Fig. 4), taking into account the lighting conditions in order to obtain textured 3D models (models with radiometric information) with accurate shape and accurate radiometric information without blur, shadows or reflection effects.
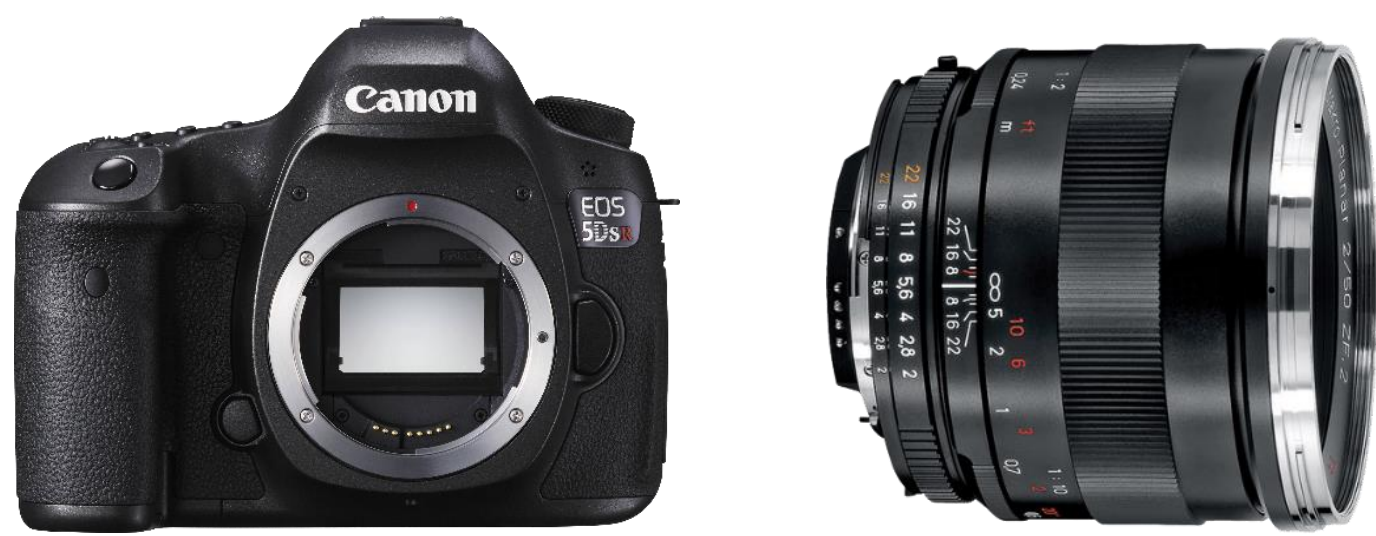

Fig. 4: Canon EOS 5DSR DLSR Camera with a Zeiss 50 mm macro lens.

\begin{tabular}{|l|l|}
\hline Model & Canon EOS 5DSR \\
\hline Sensor & CMOS 50.3 [Mp] \\
\hline Sensor size & $36 \times 24[\mathrm{~mm}]$ \\
\hline Image size & $8688 \times 5792[$ pixels] \\
\hline Lens & Zeiss ZE/ZF.2 Makro-Planar T* $50 \mathrm{~mm} \mathrm{f/2}$ \\
\hline Focal length & $50[\mathrm{~mm}]$ \\
\hline
\end{tabular}

Table 2: Main characteristic of the Employed camera and lens

\section{LiDAR approach}

As stated above, about the LiDAR approach, a triangulation-based laser scanner was used. In this type of scanner, an emitter projects a laser light to the target object, then, a sensor receives the reflected light and the distance from the object to the scanner is computed using trigonometric triangulation (Fig. 5). 


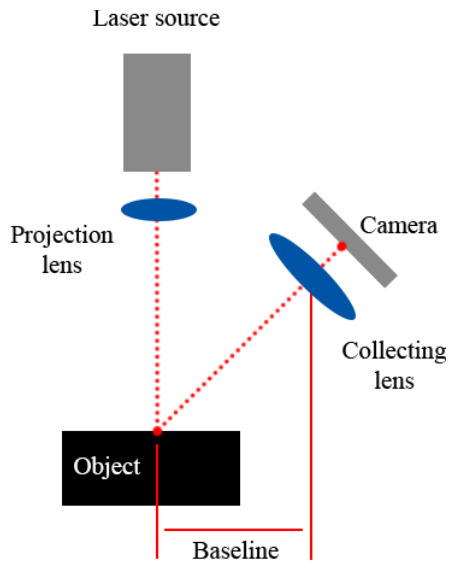

Fig. 5: Synthetic scheme of the functioning of a triangulation-based laser scanner.

\subsection{Data acquisition}

The operative workflow was adapted from the standard procedure used in Arvedi Laboratory for the digitalization of historical violins (Dondi et al. 2017). Firstly, the musical instrument to digitalize is fixed to an ad-hoc support, since it is crucial that it stays still during the acquisition. Multiple scans are needed to acquire the complete surface, depending on the dimension and the morphological characteristics of the target object. When all the visible area of the instrument is acquired, it was turned and fixed again to the support to acquire the other side (for example, firstly the right side, then the left side). To connect the various sides at the end of the acquisition, it is important to include some anchor points during the acquisition. According to the object, the time needed for this scanning process ranges from half an hour to two hours.

After the acquisition and the connection of the various side of the object the raw scans are cleaned for removing redundant parts (Fig. 6). Depending on the complexity of the object acquired, the time needed for this procedure goes from one to two hours.

\subsection{Data processing}

The cleaned clouds of points are then triangularized to produce the 3D mesh of the instrument. Once the mesh is created, it is necessary to fix it by filling holes, removing some topological errors and reconstructing some small missing parts (Fig. 7). Needed time for this phase of the work goes from three to ten hours (naturally according to the dimension of the scanned object as well). 

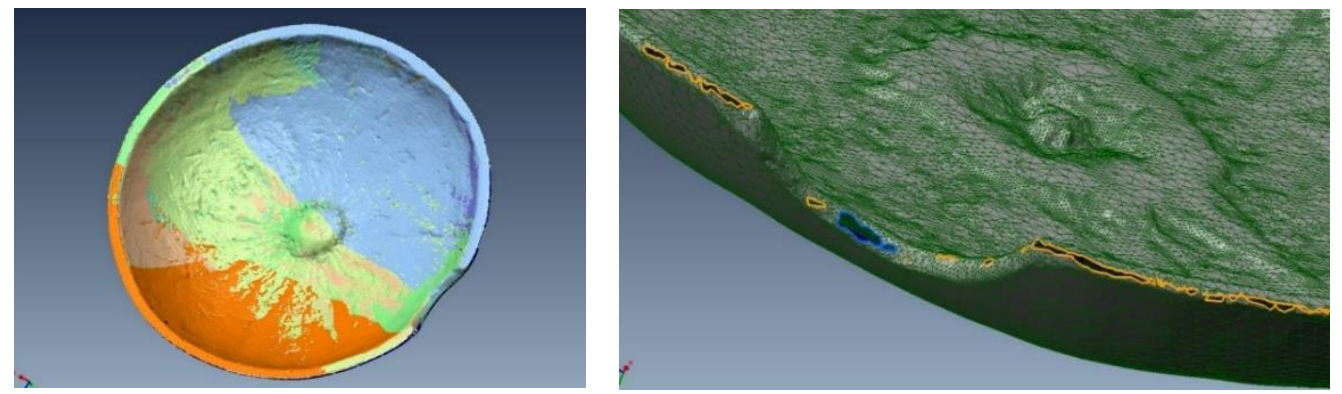

Fig. 6-7: On the left, removing of redundant or wrong scans. On the right, closing holes and reconstruction of small missing areas.

The models generated by using this approach are very detailed and rich of information about the geometry of the object (Fig. 8). Accurate measurements can be performed directly on the models since this approach provide metric information to the users with a submillimetre accuracy.

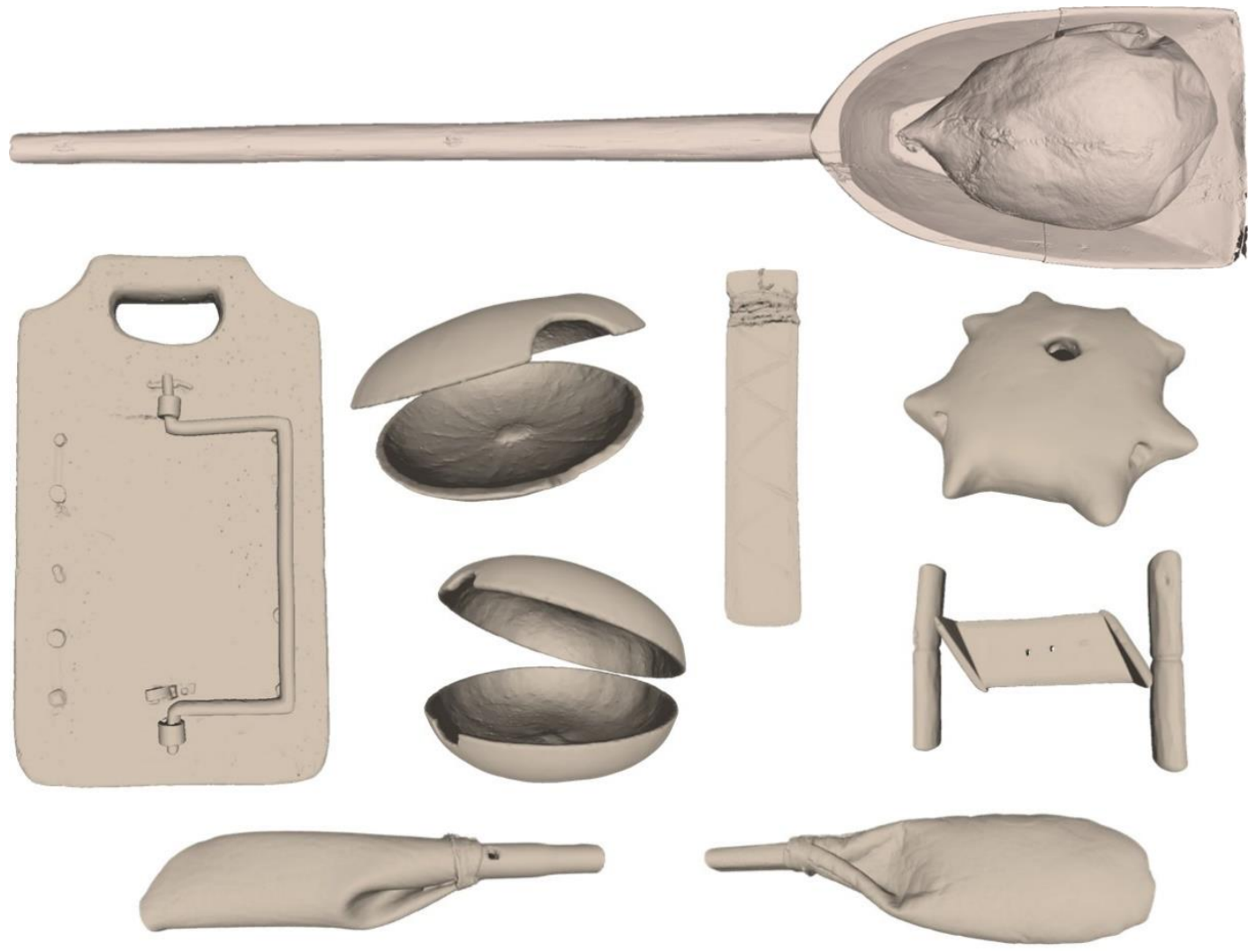

Fig. 8: Final results (3D models obtained by the LiDAR acquisitions). 
In certain circumstances, the adopted scanner was not able to completely acquire some parts of the instruments. The following cases have been observed during acquisition:

- Areas unreachable by the laser signal (for the morphology of the object).

- Very dark or shade areas.

- Areas where it is possible to observe an abrupt change of colour (from bright to dark, for example where there is a change of material), because before the acquisition the laser need to be calibrated on a specific radiometric value.

\section{Photogrammetric approach}

The research group of Geomatics Lab for Cultural Heritage of Polytechnic University of Turin performed a close-range photogrammetric acquisition on the same music instruments. This approach represents a consolidated survey method, with the added benefit that the acquisitions are fast and non-invasive (Guerra et al. 2018; Kersten and Lindstaedt 2012). Structure from Motion technique was chosen in order to get a high-resolution 3D mesh of the music instruments.

Structure from Motion is an image-based technique based on the photogrammetric approach that allow the operator to perform a 3D scene reconstruction from twodimensional images of the same object taken from different point of views.

The operative workflow can be summarised in this way:

- Data acquisition. In this phase, the images are acquired.

- Keypoints extraction. During this phase the automatic matching of homologous points is performed (Westoby et al. 2012).

- Images alignment. During this step the 3D scene is reconstructed and a sparse cloud of tie points is generated (Barazzetti et al. 2010).

- Densification of the point cloud (through image-matching algorithms).

- 3D textured mesh generation.

\subsection{Data acquisition}

During the photogrammetric acquisition a photographic tripod was used; the instruments were placed on a rotating platform and artificially enlightened with two LED panel lights equipped with diffusers. Metric bars were positioned on the acquisition stage (near the instruments that need to be digitalised) in order to scale the final models generated from the captured images. The acquisition was

performed paying particular attention to images overlapping, in order to facilitate 
the automatic matching of homologous points during keypoints extraction phase (Waldhäusl et al. 2013; Samaan et al. 2013, Chiabrando et al. 2015).
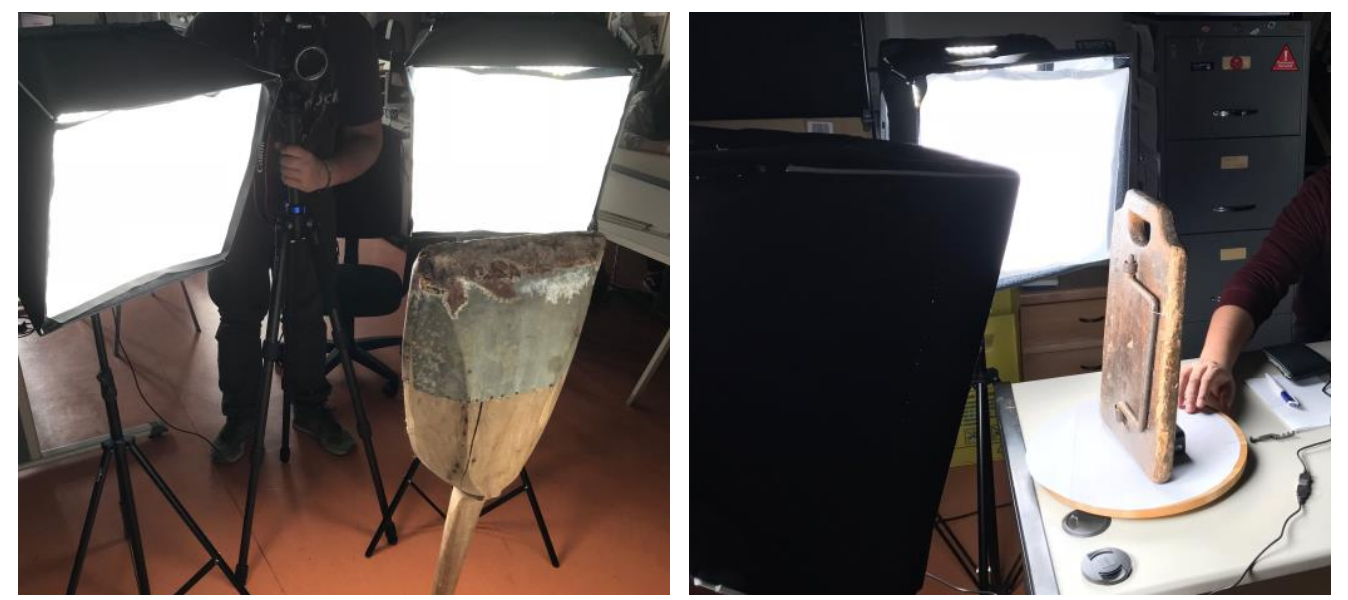

Fig. 9-10: the acquisition stage.

\subsection{Data processing}

After the images acquisition phase, datasets are processed with the commercial photogrammetric software Agisoft Photoscan (which use Structure from Motion algorithms). According to the photogrammetric pipeline first of all using the afore mentioned software the images alignment was performed (Fig. 11).
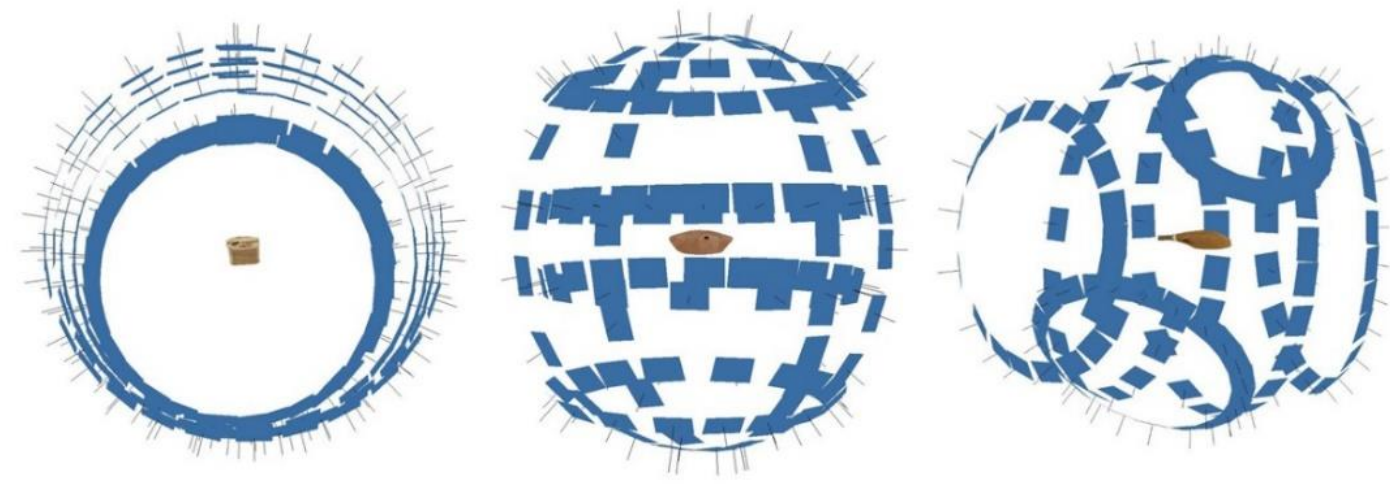

Fig. 11. Examples of three different images alignment (the photogrammetric blocks of the bull roarer, the clay whistle and one of the two hunting calls for quails).

The geometry of the acquisitions varies according to the morphological characteristics of each of music instruments that need to be digitalised. 
During image alignment phase a sparse cloud of tie points is generated; after this process, densification is performed through image-matching algorithms (Remondino et al. 2014). The product of this process is a dense point cloud from which the triangulation of a very high-resolution mesh with a very high level of detail can be performed. The last step of the process consists in the generation of a high-resolution photographic texture of the model, which provide to the users some valuable information about consistency and material of the object.

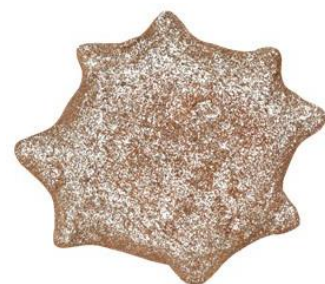

1 - Sparse cloud

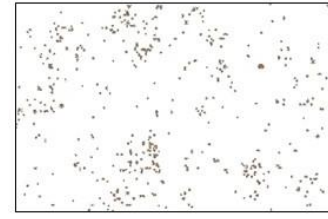

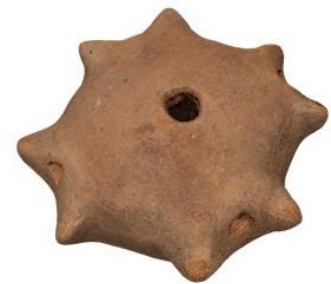

2 - Dense cloud
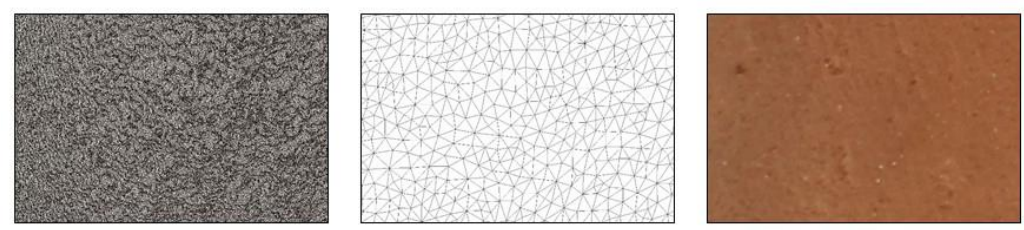

Fig. 12: steps of the photogrammetric process.

Contrary to what happen with the LiDAR system, which directly acquire data in scale 1:1, the photogrammetric model has to be scaled, since the software reconstruct the geometry of the object caught in the images but is unable to estimate its real dimensions.
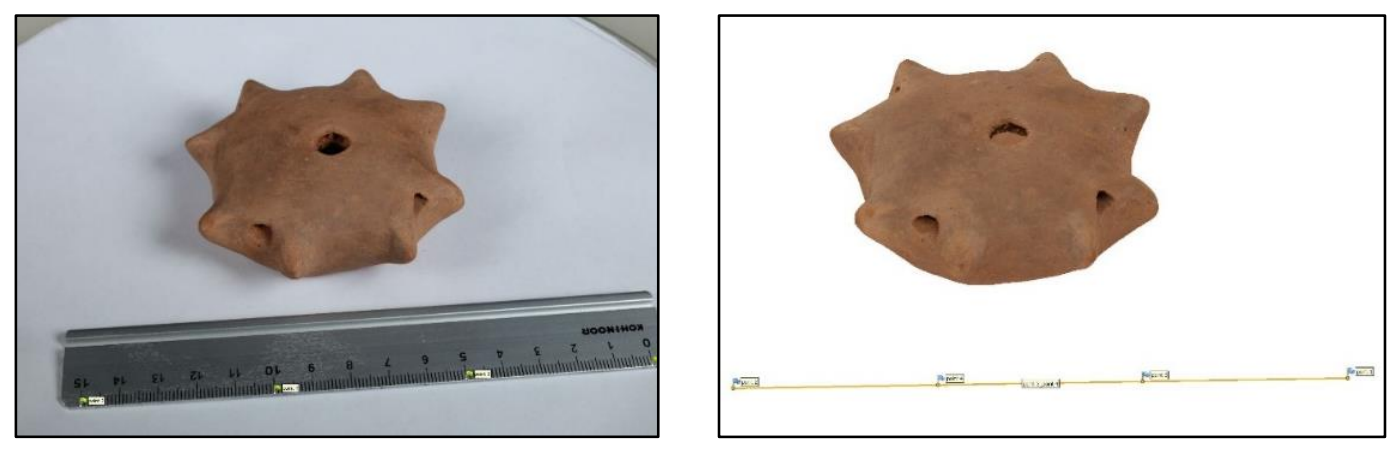

Fig. 13-14: On the left, image of the clay whistle with scale bar. On the right, scaling of the final model. 
During this experience metric bars were positioned on the stage in order to define the scale of the models (Fig. 13); in some cases, it is also possible to use some control points measured with topographic methods (for example by using a total station).
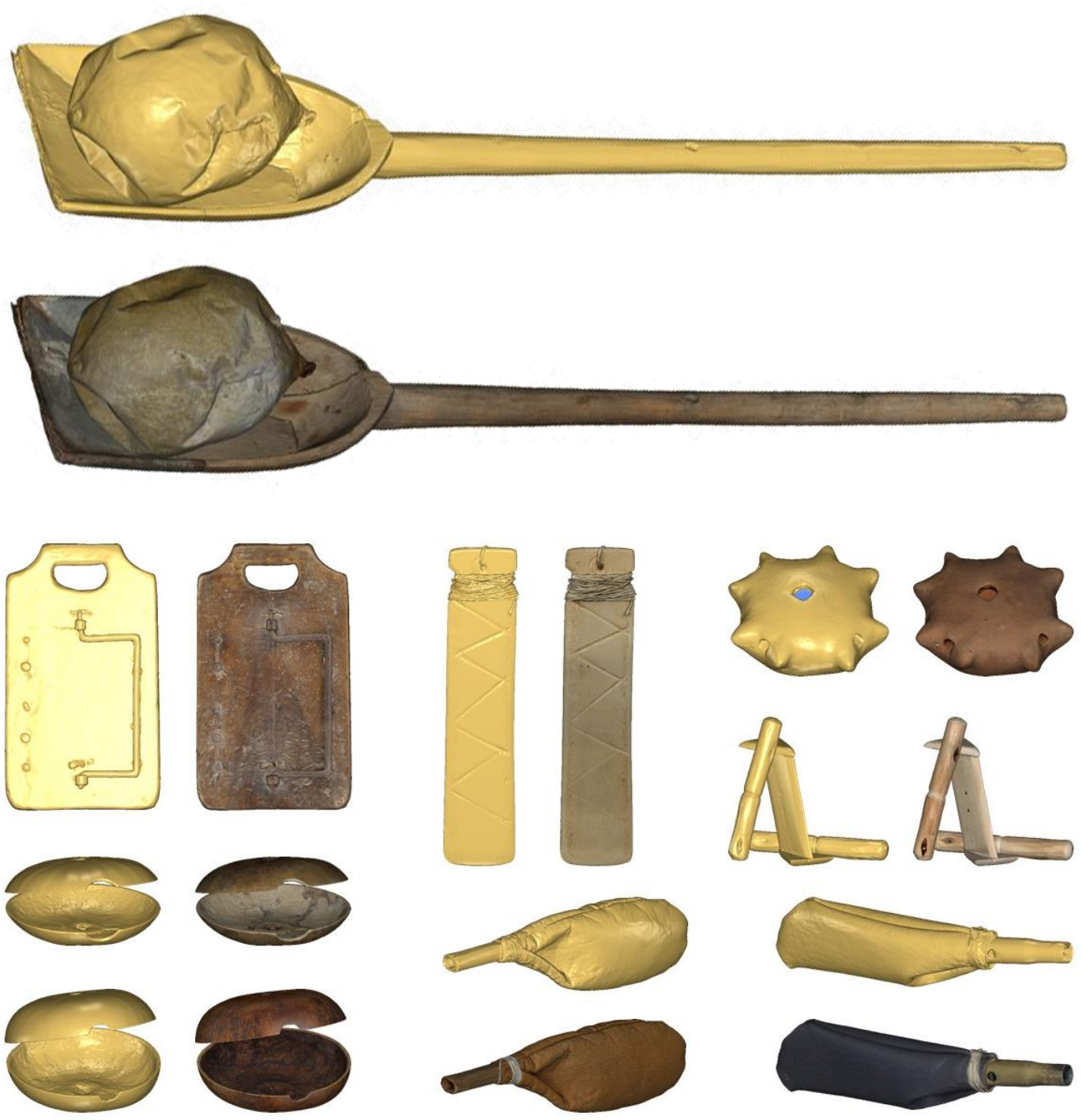

Fig. 15: Final results (3D models from photogrammetric approach). 
During the research it was possible to observe some problems related to the acquisition and the data processing of the datasets. The mobile or soft parts of the instruments are an obstacle during the acquisition of the images (in order to perform a 3D scene reconstruction it is important the object stay immovable during the acquisitions). Another issue is connected to the key point extraction phase in the areas of the object where an homogeneous texture of the material is observed, or reflective parts are present.

\begin{tabular}{|c|c|c|c|}
\hline Instrument & Images & Acquisition time & Data processing time \\
\hline Torototela & 111 & $\approx 40 \mathrm{~min}$ & $\approx 2 \mathrm{~h} 30 \mathrm{~min}$ \\
\hline Shovel & 289 & $\approx 1 \mathrm{~h} 30 \mathrm{~min}$ & $\approx 14 \mathrm{~h}$ \\
\hline Clay whistle & 125 & $\approx 25 \mathrm{~min}$ & $\approx 9 \mathrm{~h}$ \\
\hline Bull Roarer & 192 & $\approx 45 \mathrm{~min}$ & $\approx 16 \mathrm{~h} 30 \mathrm{~m}$ \\
\hline Whirling disc (frullo) & 163 & $\approx 30 \mathrm{~min}$ & $\approx 3 \mathrm{~h}$ \\
\hline Frullo handle \#1 & 79 & $\approx 15 \mathrm{~min}$ & $\approx 3 \mathrm{~h}$ \\
\hline Whirling disc handle \#2 & 65 & $\approx 15 \mathrm{~min}$ & $\approx 2 \mathrm{~h} 30 \mathrm{~min}$ \\
\hline Idiophonic mirliton (cusa) \#1 (top) & 108 & $\approx 20 \mathrm{~min}$ & $\approx 2 \mathrm{~h}$ \\
\hline $\begin{array}{l}\begin{array}{l}\text { Idiophonic mirliton (cusa) } \\
\text { (bottom) }\end{array} \\
\end{array}$ & 104 & $\approx 20 \mathrm{~min}$ & $\approx 2 \mathrm{~h}$ \\
\hline Idiophonic mirliton (cusa) \#2 (top) & 79 & $\approx 15 \mathrm{~min}$ & $\approx 1 \mathrm{~h} 30 \mathrm{~min}$ \\
\hline $\begin{array}{l}\begin{array}{l}\text { Idiophonic mirliton } \\
\text { (bottom) }\end{array} \\
\text { (cusa) \#2 }\end{array}$ & 78 & $\approx 15 \mathrm{~min}$ & $\approx 1 \mathrm{~h} 30 \mathrm{~min}$ \\
\hline Hunting call for quails \#1 & 131 & $\approx 25 \mathrm{~min}$ & $\approx 2 \mathrm{~h} 30 \mathrm{~min}$ \\
\hline Hunting call for quails \#2 & 214 & $\approx 45 \mathrm{~min}$ & $\approx 8 \mathrm{~h} 30 \mathrm{~min}$ \\
\hline $\begin{array}{l}\text { Noise maker for the Holy Week } \\
(\text { tabella })\end{array}$ & 333 & $\approx 1 \mathrm{~h} 45 \mathrm{~min}$ & $\approx 9 \mathrm{~h}$ \\
\hline
\end{tabular}

Table 3 Some detailed information of the photogrammetric process

In table 3 are summarized some some aspects connected to the realized models using the photogrammetric approach. The number of the images captured depends on the size of the object and on its morphology; to a greater number of images corresponds a longer acquisition and data processing time.

It can be observed that according to the problems before mentioned (movable or soft parts, homogeneuous texture of the material, reflective parts) as a consequence an improvement of the processing time is necessary. The two models that were time spending in terms of image acquisition and processing time, more than the others, were the shovel (for the high number of images to process) and the bull roarer (for the homogeneous texture of the wood and the presence in the upper part of the instrument of a string of rope which is a movable and very irregular component). 
On the contrary, the two parts that requested the shortest time for data processing are the two parts of the darker idiophonic mirlington. This is due to the limited number of images of their photogrammetric block (because of the small size of the instrument and its simple morphology); furthermore, the characteristics of their material consistency and their texture have facilitated the process of the homologous points extraction.

\section{3D data comparison}

In order to compare the two methods and the achieved 3D models obtained using the two different approaches, the LiDAR models and the photogrammetric models were compared on commercial software 3DReshaper (by Hexagon). By way of example, a test was conducted and eported in the present paper on the top part of one of the two cusa.
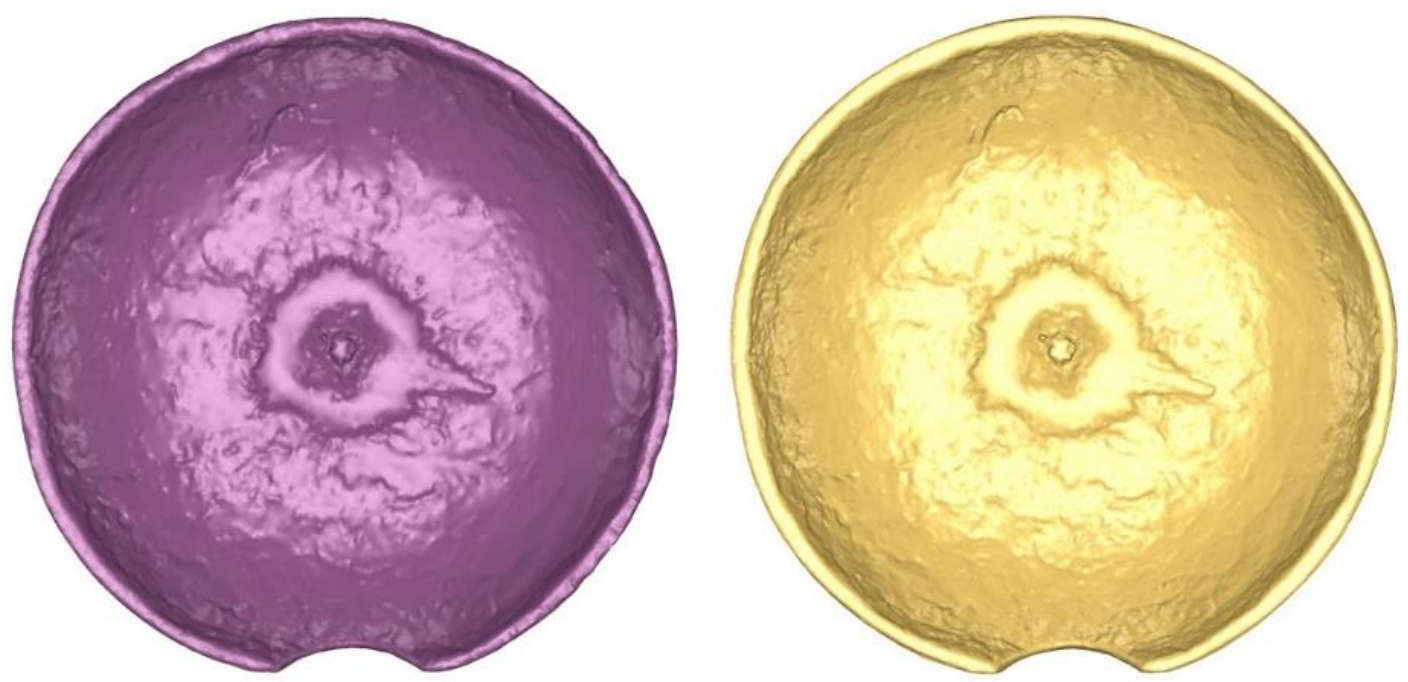

Fig. 16: On the left, mesh from LiDAR dataset; on the right, mesh from photogrammetric dataset.

Comparing the models with a mesh to mesh evaluation, it is possible to evaluate a submillimeter discrepancy (even where the discrepancy is higher, mainly in the areas where the mesh has been subjected to corrections, editing and reconstructions, the residual value is in any case below $1 \mathrm{~mm}$ ) (Fig. 17). 

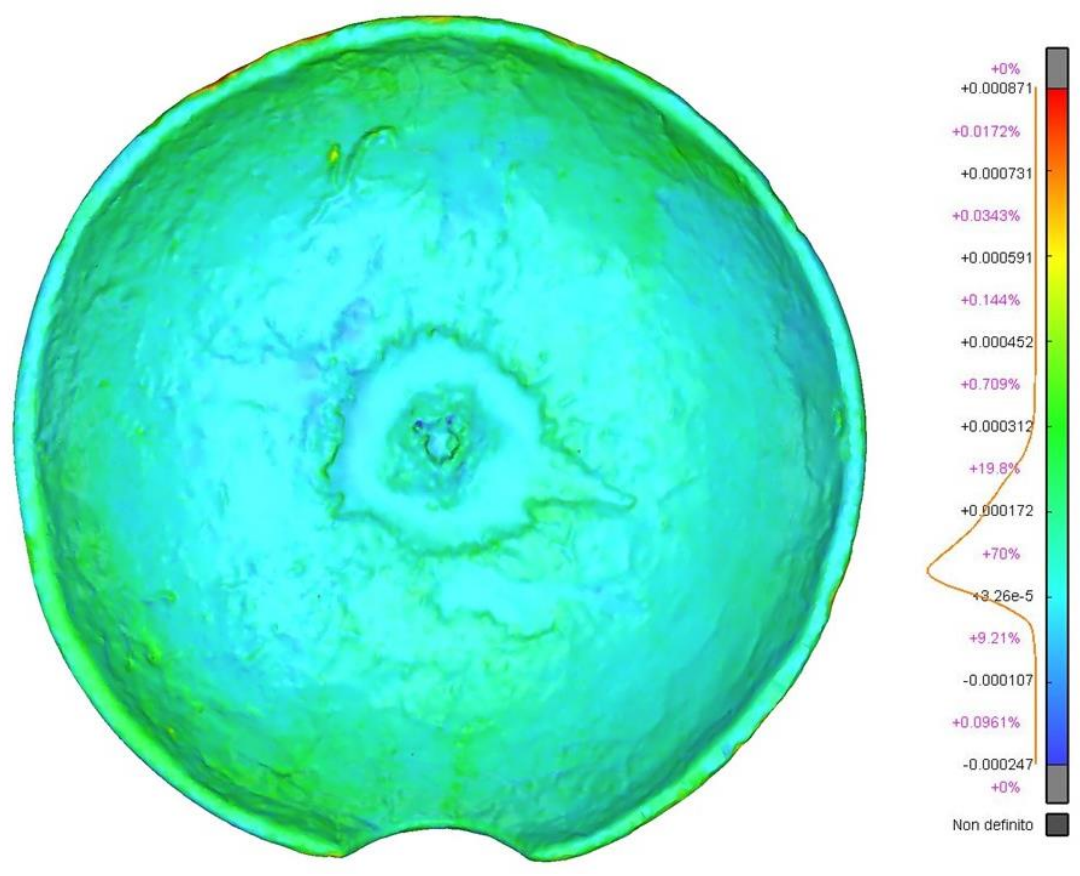

Fig. 17: Mesh-to-mesh comparison.

Afterward both the models were sectioned along the same plan; also, in this case it is possible to find submillimeter residual values (Fig. 18).

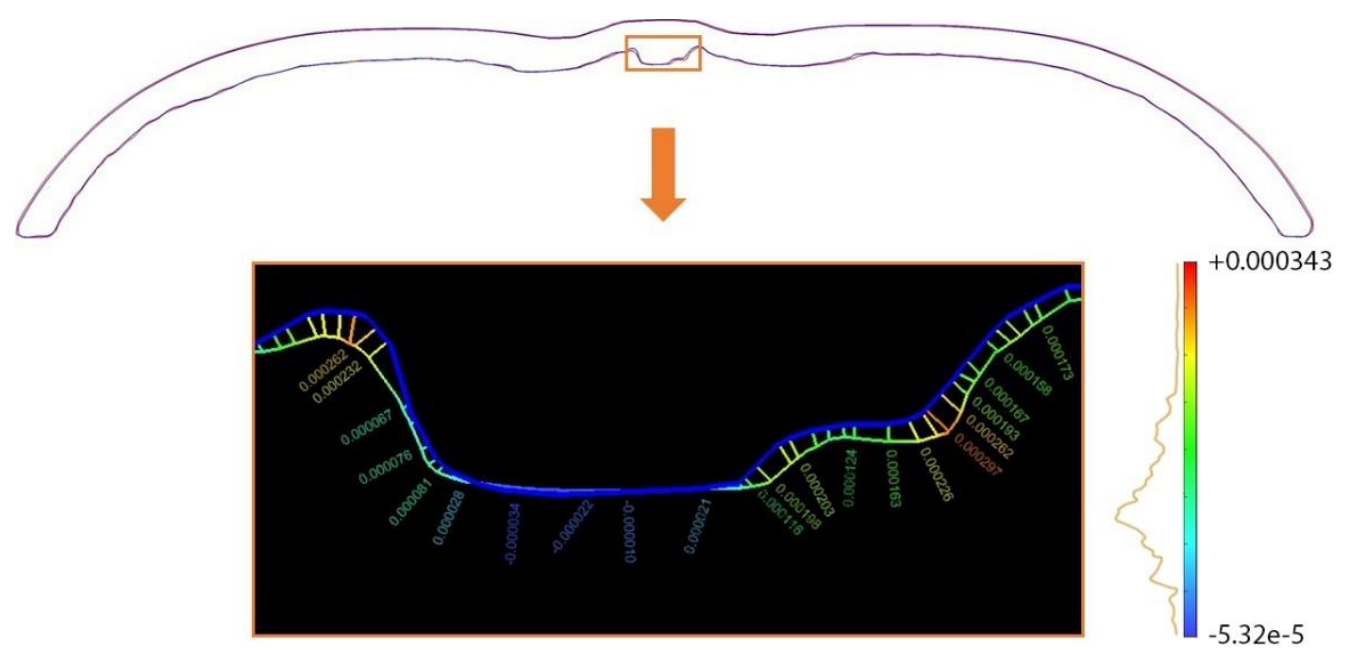

Fig. 18: Comparison between the sections. 
By considering the aim of the work, a submillimeter discrepancy can be regarded as almost insignificant, and so the accuracy of both the survey techniques used can be considered appropriate.

In conclusion, both the approaches allow the user to generate high detailed 3D models, which are metrically consistent.

\section{Conclusions and perspectives}

At the conclusion of this work it is possible to consider the pros and cons of the approaches followed during this research.

The LiDAR approach provide a very accurate mesh. With these kinds of instruments is not necessary to scale the model since the acquired are in scale 1:1. The scanner used can handle different type of materials and it is more robust to reflections. However, it is an expensive solution; the acquisition is slow and often there are problems with dark areas.

The photogrammetric approach, on the other hand, provide a high-resolution model with a high-resolution texture (which allow the users to consider the consistency of the object). Is a low-cost solution and the acquisition of the datasets is very fast. However, in order to get a good result during the acquisition, the presence of artificial lights equipped with diffusers (for the avoidance of blur, shadows or reflection effects) in almost mandatory; to scale the model, a scale bar or control points measured with topographic methods are necessary. For both the solutions a high degree of expertise is needed.

During this experience, the aim was the evaluation of the contribution of 3D modelling techniques to Cultural Heritage documentation. The implementation of new sensors and image-matching algorithms has allowed us to produce 3D highresolution models with a very high level of detail. These models are a very valid tool to document and analyse different aspects of the instruments, from the geometry of the object to the consistency of the material, or any other information the operator can associate to 3D model.

As regards the future perspectives, the goals of this experience were as follows:

- Definition of a standardization of the operative workflow for movable heritage and 3D documentation.

- Implementation of the models for interactive experiences: the 3D models obtained may be implemented for augmented or virtual reality; thanks to development of technologies connected to this type of experiences, the users can visualise the models and the associated information with a simple smartphone or a tablet (Fig. 19). 


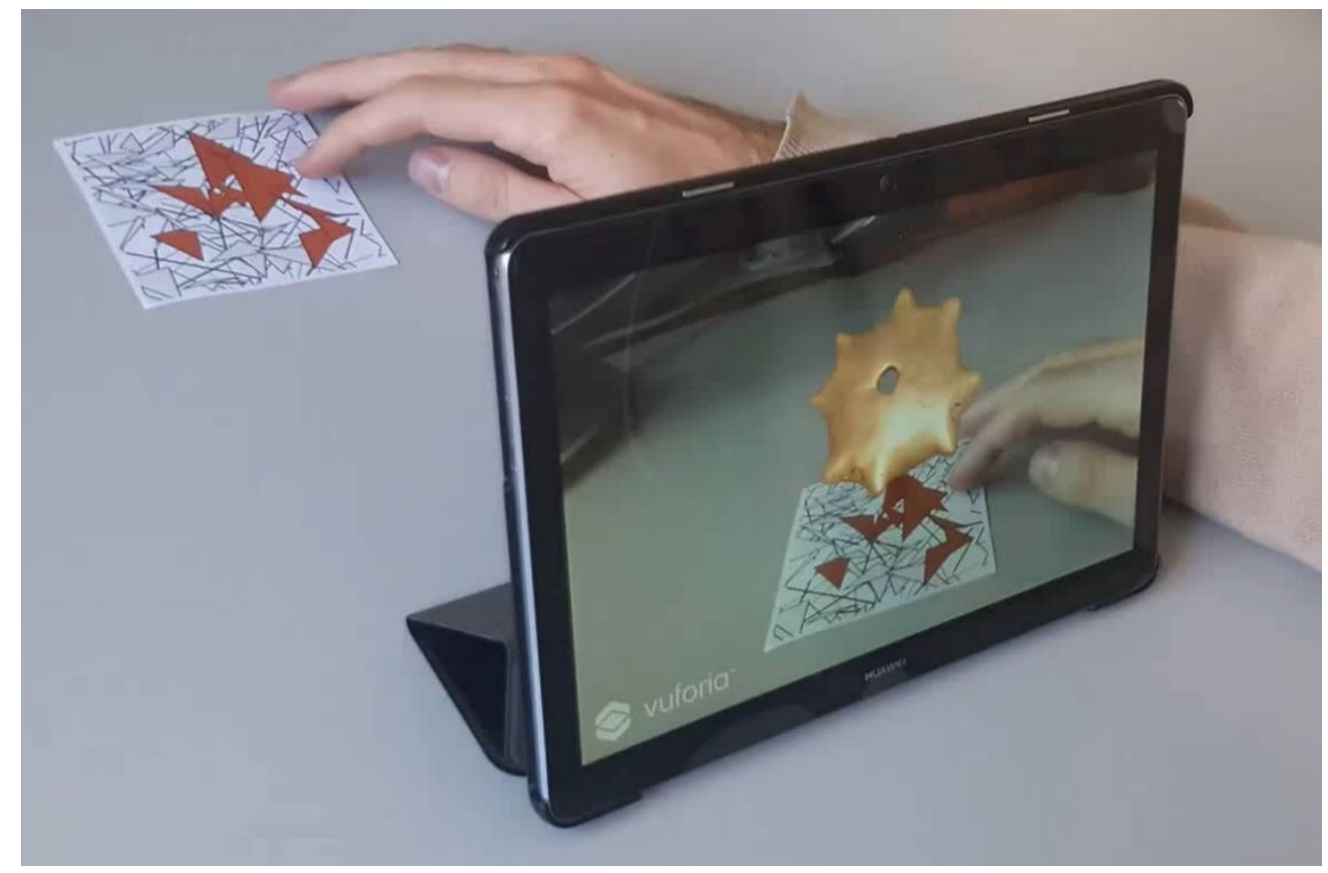

Fig. 19: Example of augmented reality on an Android Tablet.

- Documentation, 3D digital archive creation and cataloguing of movable heritage.

- Online dissemination (sharing and digital interrogation).
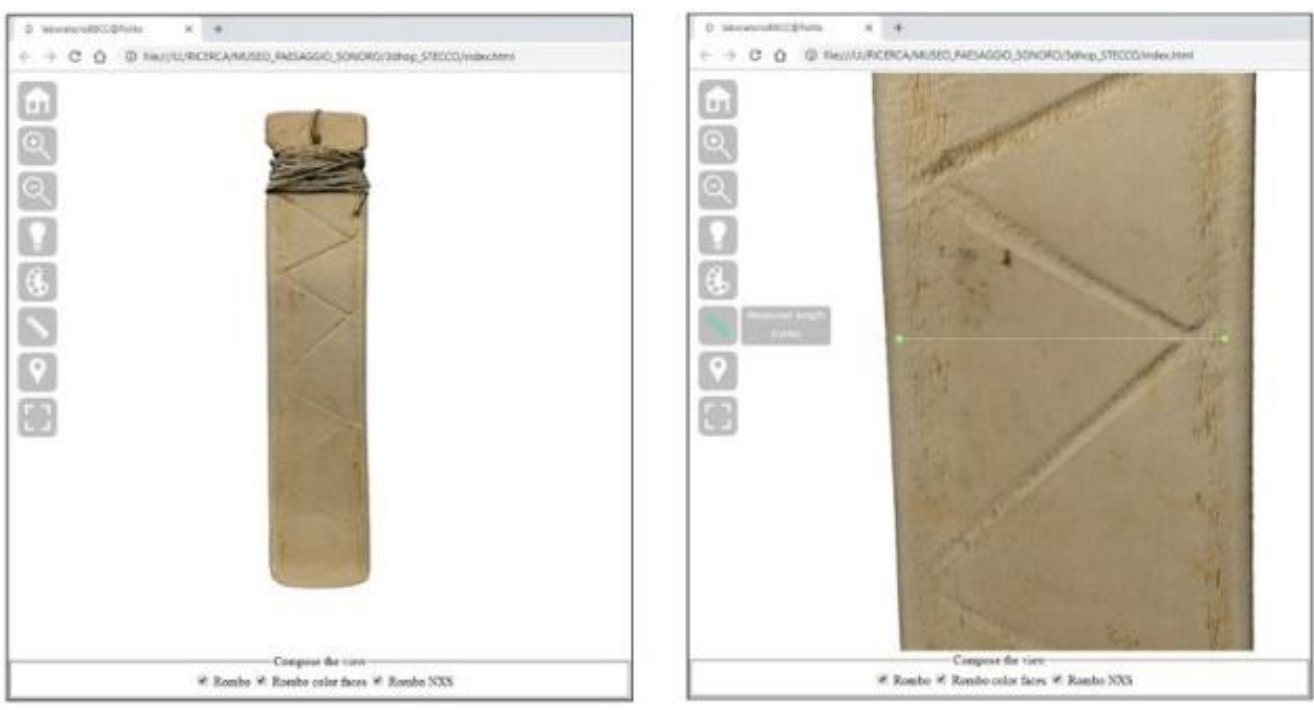

Fig. 20: 3DHOP platform (online open source viewer). 
In recent years many researchers operating in the fieldwork of 3D modelling have been focusing their interest on the creation of digital archives and on the possibility to share and visualise online models of artifacts belonging to Cultural Heritage (Koller et al. 2009; Minto and Remondino, 2014). Online viewers represent a valuable tool and a precious contribution as regards dissemination and sharing of these 3D databases. Recently multiple solutions (commercial and open-source) have been developed in order to make these contents more accessible to different kind of users.

In the Fig. 20 it is possible to see one of the models generated during this research in the platform chosen for this experience, an online open-source viewer called 3DHOP (Potenziani et al. 2015).

3DHOP platform provides the user tools that allow them to visualise the models of the instruments and can be used for online sharing and dissemination. The fruition of the model through this open-source solution can be personalized since the platform allows also non-programmers to customise the visualisation of the 3D model thanks to the Library of available JavaScript functions.

There are some useful implemented tools, which allow the users to customise the visualisation of the model (colour of the mesh, direction of virtual lights, and other customisation). For example, it is possible to see the model with the texture (for example if is necessary to consider the consistency of the material of the object, the texture is a valid help) or without (if is necessary to focus on the geometry, sometimes the texture can be a distraction).

Some interrogations may be performed directly on the model (like for example metric measurements). It is also possible associate specific information to the visualised mesh in order to share any information associate to the models.

The work on the capabilities of this kind of online sharing is actually on going.

\section{References}

Adami, A., Balletti, C., Fassi, F., Fregonese, L., Guerra, F., Taffurelli, L., Vernier, P. (2015). The bust of Francesco II Gonzaga: from digital documentation to 3D printing. ISPRS Annals of the Photogrammetry, Remote Sensing and Spatial Information Sciences, vol. II5/W3, pp. 9-15.

Barazzetti, L., Remondino, F., Scaioni, M. (2010). Automation in 3D reconstruction: results on different kinds of close-range blocks. International Archives of the Photogrammetry, Remote Sensing and Spatial Information Sciences - ISPRS Archives, vol. XXXVIII, Part 5, pp. 55-61. 
Chiabrando, F., Spanò, A. (2013). Points clouds generation using TLS and densematching techniques. A test on approachable accuracies of different tools. ISPRS Annals of the Photogrammetry, Remote Sensing and Spatial Information Sciences, vol. II5/W1, pp. 67-72.

Chiabrando, F., Donadio, E., Rinaudo, F. (2015). SfM for orthophoto generation: a winning approach for cultural heritage knowledge. International Archives of the Photogrammetry, Remote Sensing and Spatial Information Sciences - ISPRS Archives, vol. XL5/W7, pp. 91-98.

Campomanes-Alvarez, B. R., Damas, S., Cordon, O. (2012). Mesh simplification for $3 D$ modeling using evolutionary multi-objective optimization. In 2012 IEEE Congress on Evolutionary Computation, pp. 1-8.

Di Pietra, V., Donadio, E., Picchi, D., Sambuelli, L., Spanò, A. (2017). Multisource 3D models supporting ultrasonic test to investigate an egyptian sculpture of the archaeological museum in Bologna. International Archives of the Photogrammetry, Remote Sensing and Spatial Information Sciences, Vol. II-5/W1, pp. 259-266.

Dondi, P., Lombardi, L., Malagodi, M. Licchelli, M. (2016). Measuring Stradivari violin "Cremonese" (1715) by 3D Modeling. Proceedings of 2nd IMEKO International Conference of Metrology of Archaeology and Cultural Heritage (MetroArcheo 2016), pp. 29-33,

Dondi, P., Lombardi, L., Malagodi, M., Licchelli, M. (2017). 3D modelling and measurements of historical violins, ACTA IMEKO, Vol. 6, No. 3, pp. 29 - 34.

Guerra, M. G., Volpone, C., Galantucci, L. M., Percoco, G. (2018). Photogrammetric measurements of $3 D$ printed microfluidic devices. Addititive Manufacturing 2018, 21, pp. 53-62

Guidi, G., Malik, U. S., Frischer, B., Brandoni, C., Paolucci, F. (2017). The Indiana University-Uffizi project: Metrologica! challenges and workflow for massive 3D digitization of sculptures. Virtual System \& Multimedia (VSMM), 2017 23rd International Conference, pp. 1-8.

Kersten, T., Lindstaedt, M. (2012). Potential of automatic 3D object reconstruction from multiple images for applications in architecture, cultural heritage and archaeology. International Journal of Heritage in the Digital Era, vol. 1, no. 3, pp. 399-420. 
Kersten, T., Omelanowsky, D., Lindstaedt, M. (2016). Investigations of Low-Cost Systems for $3 D$ Reconstruction of Small Objects. In Euro-Mediterranean Conference, pp. 521-532. Springer, Cham.

Koller, D., Frischer, B., \& Humphreys, G. (2009). Research challenges for digital archives of $3 D$ cultural heritage models. Journal on Computing and Cultural Heritage (JOCCH), 2(3), 7.

Minto, S., Remondino, F. (2014). Online access and sharing of reality-based 3D models. SCIRES-IT-SCIentific RESearch and Information Technology, 4(2), pp. 17-28.

Potenziani, M., Callieri, M., Dellepiane, M., Corsini, M., Ponchio, F., \& Scopigno, R. (2015). 3DHOP: 3D heritage online presenter. Computers \& Graphics, 52, pp. $129-141$.

Povroznik, N. (2018). 3D Models of Ancient Greek Collection of the Perm University History Museum. In Digital Cultural Heritage, pp. 144-154. Springer, Cham.

Remondino, F. (2011). Heritage recording and 3D modeling with photogrammetry and $3 D$ scanning. Remote Sensing, 3(6), pp.1104-1138.

Remondino, F., Spera, M. G., Nocerino, E., Menna, F., \& Nex, F. (2014). State of the art in high density image matching. The Photogrammetric Record, 29(146), 144-166.

Samaan, M., Héno, R., Pierrot-Deseilligny, M. (2013). Close-range photogrammetric tools for small 3d archaeological objects. International Archives of the Photogrammetry, Remote Sensing and Spatial Information Sciences, vol. XL5/W2, pp. 549-553.

Waldhäusl, P., Ogleby, C., L., Lerma, J., L., Georgopoulos, A. (2013). $3 \times 3$ rules for simple photogrammetric documentation of architecture. URL: http://cipa.icomos.org/wp-content/uploads/2017/02/CIPA_3x3_rules_2013 1018.pdf

Westoby, M. J., Brasington, J., Glasser, N. F., Hambrey, M. J., Reynlods, J. M. (2012). 'Structure-from-Motion' photogrammetry: A low-cost, effective tool for geoscience applications. Geomorphology, vol. 179, pp. 300-314 